\title{
Islam y espacio público: una aproximación etnográfico-virtual a la celebración de la ruptura del ayuno (Iftar) en Granada
}

Islam and public space: an ethnographic-virtual approach to the celebration of the rupture of the fast (Iftar) in Granada

\author{
Paula Martín-Godoy* \\ *Universidad de Granada - Granada, Andalucía, España \\ Investigadora en el Instituto de Migraciones \\ paula21@correo.ugr.es
}




\title{
Resumen
}

En este texto se realiza una síntesis de la institucionalización del Islam en España y una breve contextualización de las diferentes comunidades musulmanas en la ciudad de Granada. La intención del mismo es presentar una aproximación de los principales discursos acerca de la presencia del Islam y de los diferentes colectivos musulmanes en el espacio público. Discursos presentes en los medios de comunicación y en los espacios virtuales que son generadores de opinión pública y constructores y legitimadores de realidades. Tras los ataques terroristas en Europa, la islamofobia creciente es uno de los tipos de racismo cultural (Wieviorka, 2006) más patentes y latentes fomentado por ciertos sectores de población. El estudio se centra principalmente en un análisis discursivo de los últimos debates emergentes en las redes virtuales relacionados con la presencia del Islam en los espacios públicos de la ciudad granadina.

Palabras clave: islamofobia; espacio público; discursos de alteridad; espacios virtuales.

\begin{abstract}
This text makes a synthesis of the institutionalization of Islam in Spain and a brief contextualization of the different Muslim communities in the city of Granada.The intention is to present an approximation of the main speeches about the presence of Islam and the different Muslim groups in the public space. Discourses present in the media and in virtual spaces that are generators of public opinion and builders and legitimators of realities. After the terrorist attacks in Europe, the growing Islamophobia is one of the types of cultural racism (Wieviorka, 2006) more patent and latent encouraged by certain sectors of the population. The study focuses mainly on a discursive analysis of the latest emergent debates in the virtual networks related to the presence of Islam in the public spaces of the city of Granada.
\end{abstract}

Keywords: islamophobia; public space; discourses of otherness; virtual spaces. 


\section{España y la religión}

Las diferentes formas de legislar la religión están sujetas al desarrollo de las relaciones entre religión y estado. La relación entre religión y estado en el contexto español está muy marcada por la tradición del nacional-catolicismo herencia del periodo de dictadura franquista (1939-1975). Aunque, señalado por Moreras y Tarrés (2013), en el régimen dictatorial también se fomentaba la práctica islámica en pequeñas dosis, como por ejemplo construyendo mezquitas o permitiendo las celebraciones de diversos rituales; pero la religión del estado era el catolicismo. También se financiaron intercambios estudiantiles en España con Marruecos y Oriente Próximo siendo, como apuntan Tarrés Chamorro y Rosón Lorente (2017), la Universidad de la ciudad de Granada una de las principales receptoras de estos estudiantes y a través de la que se creó la Asociación de Estudiantes Musulmanes en España (o Unión Estudiantil Musulmana en España). Tras finalizar el régimen de Franco y dar paso a la transición democrática (1975-1978), arrastrando aspectos residuales del anterior régimen, se produjo una transformación del sistema político hacia una democracia que pretendía impulsar un proceso de secularización del estado español; aunque no se puede hablar de que se hubiese producido un proceso de desinstitucionalización de la iglesia católica, ya que esta mantenía privilegios estatales y constitucionales. ${ }^{1}$ Como uno de los mayores beneficios en su relación se puede apuntar que ha sido la "única religión que ha podido definir, desarrollar y puntualizar sus derechos directamente con el Estado español mediante acuerdo oficial" (Dietz, 2008, p. 19). En este sentido no se puede hablar de una transición política en el sentido de transición a la diversidad o diversificación social.

La institucionalización del Islam en España ha sido un proceso que se ha ido conformando lentamente en cuanto a los procesos jurídicos, pero aún más ralentizado en su puesta en práctica. La Ley $44 / 1967$ por la que se regula el ejercicio del derecho civil a la libertad en materia religiosa es la primera ley que reconoce el derecho a la libertad religiosa, aunque remarcando en su artículo segundo la religión católica como la religión del estado. Un año después se creó el Registro de Asociaciones Confesionales no católicas y de ministros de culto no católicos

1 Es la única comunidad religiosa mencionada en la Constitución Española de 1978. 
en España, y en esta etapa comenzó a reconocerse la religión islámica como la segunda principal religión en España, aunque atribuida a los colectivos de extranjeros (Tarrés Chamorro; Rosón Lorente, 2017). Por su parte la Constitución Española de 1978 en su artículo 16 también garantiza la libertad religiosa indicando que "ninguna confesión tendrá carácter estatal", pero señalando que se mantendrán las relaciones de cooperación con la iglesia católica y otras confesiones. Para finales de los años setenta ya existía en el registro de entidades religiosas del Ministerio de Justicia alrededor de cuarenta entidades musulmanas inscritas. ${ }^{2}$ La LO 7/1980 (España, 1980) derogó la ley 44/1967 y mediante esta se forma la Comisión Asesora de libertad religiosa de la que entra a formar parte la Asociación Musulmana de España (AME), como representante del Islam en España.

En el año 1989 la AME presentó una petición al director general de asuntos religiosos para declarar el Islam como una religión de notorio arraigo. El resultado fue aceptado favorablemente por unanimidad con los siguientes argumentos: la gran presencia histórica del Islam en España (presente desde el S.VIII); ser una religión mayoritaria a nivel mundial; la proximidad geográfica con el territorio africano; y el aumento de fieles debido a los flujos migratorios. El estado español exigía un único interlocutor de las diferentes comunidades islámicas pertenecientes a diferentes corrientes del Islam, por lo que se formó la Federación Española de Entidades Religiosas Islámicas (FEERI). Al poco tiempo la AME se separó de la FEERI y se creó la nueva federación: la Unión de Comunidades Islámicas de España (UCIDE), y entre ambas agrupaban a la mayoría de comunidades inscritas en el registro de entidades religiosas del Ministerio de Justicia. Aunque tras la insistencia del estado español en dialogar con un solo interlocutor se creó la Comisión Islámica de España (CIE), firmando el primer acuerdo de cooperación en 1992 (Ley 26/1992) por el que se amparan los derechos para los ciudadanos musulmanes españoles. ${ }^{3}$ Tras un proceso de dificultades para alcanzar el reconocimiento sociopolítico,

2 Según la Unión de Comunidades Islámicas de España (UCIDE, [s.d.]), las primeras asociaciones islámicas fueron la de Melilla en 1968, la de Ceuta en 1971 y en la península, en Madrid en 1968 la Asociación Musulmana de España (AME) con inscripción en 1971.

3 "Se tratan aspectos como los espacios de culto (mezquitas y cementerios), el estatuto de los imames, los efectos civiles de los matrimonios islámicos, la educación religiosa en las escuelas públicas, las fiestas religiosas, la alimentación, la asistencia espiritual en hospitales y prisiones, así como la conservación y fomento del patrimonio histórico-artístico y cultural islámico" (Tarrés Chamorro; Rosón Lorente, 2017, p. 182). 
actualmente los obstáculos y las luchas por los derechos pertenecientes a la población musulmana siguen vigentes. Un ejemplo de ello son las demandas en educación, en el mundo laboral, las manifestaciones contra el odio y la islamofobia, o los diferentes intentos de compartir aspectos culturales con el resto de la sociedad.

La opinión pública no juega un papel moderador o neutral en este proceso. Tanto los discursos políticos como los de los medios de comunicación, tras los diferentes atentados en Europa ${ }^{4}$ de combatientes fieles a Daesh, han favorecido al aumento de islamofobia, xenofobia y arabofobia en la sociedad española (Observatorio Andalusí, 2017a). Ya el 11S produjo una atmósfera de rechazo y de desconfianza hacia lo árabe-musulmán que se transformó a través de los discursos y las prácticas en una alarma social contra el "otro" islamicus. Siguiendo a Noor (2012) podemos decir que los rasgos más destacados del discurso de la guerra contra el terror se basan en un orden mundial monocromo en el que Occidente es superior al "otro", en este caso el enemigo del Islam; la frontera entre ambas civilizaciones es violenta por lo que no es considerado el diálogo; la irracionalidad del "otro" es otra característica a destacar y, finalmente, las perspectivas de comunidad y seguridad cerradas. Moreras (2005) también expone cómo los diferentes gobiernos presididos por el Partido Popular (PP), partido de carácter conservador, han contribuido a una mayor estigmatización y criminalización de los colectivos de inmigrantes. Los discursos del PP en relación al fenómeno migratorio comenzaron a hacer hincapié en los aspectos culturales resaltando la diferencia del Islam y los musulmanes con el concepto de "cultura nacional", dificultando entre otras cuestiones el proceso de acomodación de las diferentes comunidades y generando construcciones que diferencian y distancian a unos de otros. Esta tendencia a la diferenciación $u$ otrificación ${ }^{5}$ y a construir una percepción de la existencia de conflicto entre

4 París (Enero del 2015 y Noviembre de 2015), Estambul (Enero del 2016 y Junio del 2016), Bruselas (Marzo del 2016), Ansbach (Julio de 2016), Niza (Julio de 2016), Berlín (Diciembre de 2016), Londres (Marzo y Junio de 2017), Estocolmo (Diciembre de 2010 y Abril del 2017), Manchester (Mayo del 2017) y Barcelona (Agosto de 2017).

5 "Otrificación remite a una de las estrategias discursivas utilizadas por el colonialismo europeo, iniciado a finales del siglo XIX en África, para considerar a los individuos y / o grupos humanos extraeuropeos como inferiores, salvajes, etc., apelando a la categoría de 'otros' como 'los que poseen características diferentes', sobre todo en lo referido a fenotipo, cultura, etc. Así, la otrificación demarcó una clara línea divisoria entre 'nosotros' y 'los otros' para jerarquizar a un grupo humano en desmedro de otro, que quedó racializado e inferiorizado" (Arduino, 2016, p. 132). 
la tradición musulmana y los valores de la sociedad española o andaluza (Rosón Lorente, 2002) también se produce en los medios de comunicación. Una de las estrategias más empleadas es la utilización de términos como "musulmán", "Islam", "islámico", "islamista" o "yihadista" sin ningún tipo de criterio y en relación a contenidos violentos para generar una imagen del Islam como amenaza.

Sin embargo, en España el concepto islamofobia comenzó a utilizarse cuando las comunidades islámicas estaban más visibilizadas, como apunta Rosón Lorente (2012), después de los actos de Ceuta, El Ejido, Ca n'anclada y Premià de Mar, ${ }^{6}$ siendo etiquetados y considerados en los últimos estudios como actos islamófobos. Podemos señalar el inicio del siglo actual como una etapa en la que los discursos y las ideas xenófobas, racistas e islamófobas han crecido como reacción a la inmigración de musulmanes y árabes en las últimas décadas; este aumento de la islamofobia es mayormente empujado por ciertos sectores de identidad política ultraderechista o derechista (Observatorio Andalusí, 2017b). Uno de los espacios protagonistas en esa generación y reproducción de discursos de odio es internet; el Informe Anual sobre Islamofobia en España (Observatorio Andalusí, 2017b) señala que los medios de comunicación resaltan las creencias religiosas en función de si se trata de víctimas o de delincuentes, siendo en este último caso en el que se subraya la adscripción religiosa, principalmente la musulmana, o la nacionalidad o la situación administrativa. Según el informe, las principales víctimas de los delitos de odio son las comunidades musulmanas en general, seguido de las mujeres musulmanas y las mezquitas en tercer lugar; siendo las conductas de odio más prevalentes las campañas, propaganda, música del odio y las agitaciones en redes y activismo. Internet, las redes sociales y los medios de comunicación se convierten así en los lugares en los que se producen mayormente las incitaciones al odio.

Desde los ataques del 11S podemos señalar dos tendencias en la opinión pública en relación a la presencia de comunidades musulmanas. Por un lado, hay que señalar las diversas manifestaciones de islamofobia y arabofobia que surgen del temido "regreso del Islam"; y por otro, la convicción de que

6 Para profundizar más sobre el conflicto de El Ejido, véase Checa Olmos (2001). Para el caso de Ceuta (1995), véase Rosón Lorente (2012). Para el caso de Tarrasa y Premià de Mar en Cataluña, veáse Moreras (2004). 
la pluralidad religiosa “'llegó para quedarse' y de que los musulmanes deben ser integrados mediante una 'hispanización' o una 'europeización' del Islam inmigrado" (Dietz, 2008, p. 13).

\section{Granada $^{7}$ y el Islam hoy}

La presencia del Islam en territorio andaluz y más concretamente granadino se remonta a siglos de historia. Granada ha sido históricamente un territorio de presencia de diversidad religiosa y convivencia, por ello siendo el último enclave musulmán en la península se ha apreciado como relevante para el Islam español (Alcantud, 2008). El territorio conocido como Al-Ándalus data del siglo VIII y fue conformado por los territorios dominados por los árabes y bereberes musulmanes; con el asentamiento de bereberes norteafricanos (Ziríes) a finales del S.X el territorio de Ilbira pasó a ser el reino de Granada. En el S.XI, y tras varios intentos, los Almorávides ocuparon el territorio de Granada frenando el avance cristiano, pero tuvieron que aliarse con los Almohades, quienes finalmente tomaron el poder del reino. Tras la marcha de estas comunidades y las disputas por el territorio entre señores musulmanes, se fundó la dinastía nazarí de Granada (en 1237 por Muhammad B. Nasr) que culminó con la entrega de Granada a los reyes católicos (1492) (Álvarez de Morales y Ruiz Matas, 2008). Todos estos encuentros y desencuentros entre las diferentes comunidades están muy presentes en la construcción simbólica de la ciudadanía, así como en la arquitectura y en la distribución espacial de la ciudad.

El aumento de los fieles al Islam responde tanto al nacimiento de españoles de padres inmigrantes, que pueden heredar, en términos culturales, o no las creencias religiosas; como a la conversión de españoles y la migración procedente de África. La conformación de comunidades musulmanas en Granada era notable antes de que los inmigrantes fuesen visibilizados, siendo descrito como un territorio clave en la aparición de asociaciones islámicas en la esfera pública ${ }^{8}$

7 Granada es una ciudad situada en la comunidad autónoma de Andalucía, al sur de España. Cuenta con un total de 234.758 habitantes (Junta de Andalucía, 2016).

8 En 1966 surge del impulso de estudiantes el "Centro Islámico de Granada” y en 1980 la "Sociedad para el Retorno del Islam en España” (López Chaves, 2010). 
(López Chaves, 2010). En la década de los noventa es cuando la conformación de comunidades musulmanas es más visibilizada y consolidada debido a las migraciones internacionales, destacándose la formación de tales comunidades como el "primer punto de encuentro entre los españoles convertidos al Islam y los inmigrantes marroquíes" (Rosón Lorente, 2002, p. 49) principalmente.

En la actualidad, el municipio de Granada cuenta con una población de musulmanes de 31.775, entre españoles (14.923) y extranjeros (16.852) (Observatorio Andalusí, 2016); ${ }^{9}$ entre los colectivos de españoles musulmanes hay que tener en cuenta que están incluidos los extranjeros que hayan adquirido la nacionalidad española, los españoles musulmanes de nacimiento y las personas conversas al Islam. En este sentido destacaremos que las principales nacionalidades extranjeras en el municipio son la marroquí y la senegalesa; y la distribución residencial de estas personas en base a su nacionalidad se encuentra bastante diseminada: para la población de nacionalidad marroquí los principales distritos habitados son Norte, Beiro, Chana y en menor medida el Centro; siendo Norte, Chana y Ronda los distritos más habitados por las personas de nacionalidad senegalesa (Instituto Nacional de Estadística, 2016). Esta distribución residencial, en la que se observa una mayor presencia de la población extranjera de estas nacionalidades en las periferias de la ciudad y en algunas zonas del centro, guarda relación con las políticas urbanas y de vivienda implementadas por el Ayuntamiento de Granada y el sector privado en los últimos años.

Al inicio del siglo actual los inmigrantes y las comunidades musulmanas eran más visibilizadas en el centro de la ciudad, sobretodo en el barrio del Albayzín que fue el primer asentamiento de las comunidades musulmanas en Granada (López Chaves, 2010). Rosón Lorente (2002) en su estudio sobre la conformación de comunidades musulmanas y su relación con la población "autóctona" señala que para entender el proceso de creación de tales comunidades e identidades locales hay que tener en cuenta tres momentos históricos: la entrada en el año 711 de los árabes y bereberes musulmanes en la ciudad de Granada, la conquista de Granada por los Reyes Católicos en 1492 y la expulsión

9 Resulta de gran dificultad encontrar fuentes estadísticas fiables acerca de aspectos socio-religiosos, pues no solo las estadísticas simplifican un fenómeno tan diverso y plural, o dejan de reflejar realidades, sino que estas prácticas e identidades religiosas se encuentran en constantes procesos de cambio. A pesar de ello, las estadísticas señaladas se han considerado las más fiables para aproximarnos cuantitativamente a las poblaciones musulmanas en la ciudad de Granada. 
de los musulmanes decretada por Felipe III entre 1609-1613. Entre otras cuestiones Rosón se centra en analizar el conflicto surgido por la construcción de una mezquita que se inauguró en el año 2003 en el barrio del Albayzín y los conflictos entorno al día de la celebración de la expulsión de los musulmanes por los Reyes Católicos. ${ }^{10}$ Los principales actores, descritos por el autor, que expresan posturas son el sector muslimófobo (rechazo al "otro" musulmán) de la sociedad, el sector muslimófilo (aceptación del "otro" musulmán) y las comunidades musulmanas (Rosón Lorente, 2002).

Por otro lado, y a pesar de la tradición de convivencia interreligiosa, en este territorio siguen existiendo desigualdades estructurales (como espacios de culto, recursos educativos, relaciones políticas y financieras, etc.) que promueven las jerarquías de poder y alimentan los prejuicios y estereotipos que son fabricados en un nivel más micro por ciertos sectores de población. Según los datos actuales del Ministerio de Justicia (España, 2017) existen en el municipio de Granada unas quince comunidades musulmanas, ${ }^{11} \mathrm{y}$ en la ciudad de Granada unos seis oratorios y mezquitas, ${ }^{12}$ número impreciso en la actualidad por no contar con un registro de los centros, pero también por la cantidad de espacios de culto anónimos y ocultos que hacen de los hogares de las personas musulmanas lugares íntimos de oración. Existen otras numerosas estructuras formales comunitarias como asociaciones, cafés, tiendas de alimentación, carnicerías, baños árabes, teterías, etc; muchas de ellas convertidas en reclamo y atracción turística en el centro de la ciudad.

Respecto a las percepciones sobre las diferentes comunidades musulmanas, se ha apuntado ya que en Granada la "sociedad mayoritaria local a menudo

10 Este día es celebrado por algunos sectores de población como "el día de la toma de Granada".

11 Al-yama'a Comunidad Musulmana en Granada; Comunidad de Mujeres Musulmanas de Granada, Comunidad Islámica de Alhama de Granada; Comunidad Islámica Annur de Granada, Comunidad Islámica Clemencia; Comunidad Islámica de la Hermandad de Granada; Comunidad Islámica en España; Comunidad Islámica Felicidad; Comunidad Musulmana de Al-andalus (Comunidad Autónoma de Granada); Comunidad Musulmana Sunita de España; Comunidad Musulmana Al-Hejira; Comunidad Musulmana de Granada; Comunidad Musulmana Española de la Mezquita del Temor de Allah en Granada; Consejo Islámico de Granada y Mezquita de la Paz “As-Salam".

12 Mezquita de la Paz (o Assalam), Mezquita del Temor de All'ah (o At-Taqwa), Mezquita Masalical Jinan, Mezquita Mayor de Granada, Mezquita Omar y Centro Islámico de Granada (Blanco et al., 2004). 
muestra no un rechazo, sino una total ignorancia y un gran desinterés con respecto a los musulmanes" (Dietz, 2002, p. 6), viéndolos también como los "nuevos invasores". También se han identificado generalizaciones, como que se sigue atribuyendo la etiqueta de "mora o moro" a los hijos de inmigrantes (Olmos Alcaraz, 2017), interpretando que dicha etiqueta se asigna en función de ciertos caracteres fenotípicos de los diferentes sujetos. Actualmente se puede apuntar a cómo la presencia o visibilización de los diferentes colectivos musulmanes es percibida por ciertos sectores de la población como una invasión y una agresión a la "cultura nacional". El Observatorio Andalusí (2017b) ya recogió, tras el ataque terrorista de Marzo del 2016 en Bruselas, un incidente de grupos de extrema derecha, Núcleo Joven Granada, que fomentan el odio a lo musulmán, pero este año han sido varias las manifestaciones de odio principalmente promovidas por la reciente aparición de otro colectivo de extrema derecha, Hogar Social Granada. En este punto nos detenemos a recordar que parte de la islamofobia creciente está siendo reforzada por el desconocimiento y por el auge del discurso de la guerra contra terror (Martín Muñoz; Grosfoguel, 2012) surgidos tras los ataques del 11 de Septiembre y los últimos mencionados en Europa. Moreras (2005) ya señaló que, desde los atentados del 11 de Marzo del 2004 en Madrid, se ha pasado de la estigmatización y criminalización de la figura del inmigrante, en especial la del magrebí, ${ }^{13}$ a la estigmatización y criminalización de una religión, el Islam. ${ }^{14}$

De este modo, tenemos que señalar que han sido diversas las apariciones de las comunidades musulmanas en los espacios públicos de la ciudad de Granada en este contexto actual de estigmatización. En los siguientes apartados analizaremos los principales discursos entorno al fenómeno objeto de estudio en los medios y redes virtuales tras un conflicto detectado en la opinión pública. El conflicto analizado se generó tras la presencia de las comunidades musulmanas y la realización de un evento cultural en un espacio público de la ciudad.

13 El término "magrebí" o "magrebíes" hace referencia a la pertenecía al Magreb, una región del noroeste de África.

14 El autor expone tres ejemplo de ediciones de libros de texto en los que "tanto en la selección de títulos como en el rediseño de sus portadas [...]se está recurriendo a una serie de supuestos ampliamente asentados y compartidos por parte de la opinión pública española"(Moreras, 2005, p. 232). Siendo esta una estrategia para reforzar la visión negativa del Islam, lo diferente, la amenaza a lo que se considera cultura nacional y democracia. 


\section{Marco teórico}

Para profundizar sobre algunos conceptos, es necesario detenerse a puntualizar, que no aclarar, algunas cuestiones teóricas que continúan en la espiral de los debates actuales entorno al fenómeno abordado en este artículo.

La convivencia es una de las grandes palabras del vocabulario social en la que puede caber una amplia variedad de significados, de hecho, comúnmente se utiliza para referirse a un estado meramente de coexistencia. Tal y como se concibe en este trabajo hace referencia no solo a la presencia o coexistencia pacífica de diversos grupos de población, sino al intercambio y a la interacción social. Se trata de generar, desde una perspectiva intercultural, una unidad entre la diversidad (Giménez Romero, 2003). Para llegar a ese estado de convivencia es necesario que desde los poderes públicos se articulen recursos que promuevan la interacción y el intercambio, bajo el paradigma de la interculturalidad; ejemplo de ello serían las iniciativas de diálogo interreligioso que son una pieza clave para el diálogo intercultural. Este tipo de diálogo es un acercamiento de proximidad, reúne a los creyentes de las diversas confesiones religiosas para que se produzca un mutuo reconocimiento y respeto, rompiendo las barreras del desconocimiento y con la dificultad de entablar diálogo con quienes no creen en el mismo. Debe ser un encuentro en profundidad donde los ejes centrales sean la escucha activa y el testimonio honesto (Torradeflot, 2012).

Uno de los obstáculos destacados para llegar a ese estado de convivencia son los prejuicios y estereotipos que generan discriminación y conflicto social. El debate alrededor de la islamofobia tradicionalmente se ha dividido en dos posturas: los que consideran que es un fenómeno histórico (prejuicios y estereotipos que trascienden en los años), y quienes lo conceptualizan como una variedad de manifestaciones diferentes de discriminación hacia los musulmanes y el Islam en general (Adlbi Sibai, 2016). Desde este trabajo se defiende una postura compleja que engloba ambas perspectivas, puesto que "mientras las estructuras racistas y coloniales que sustentan el fenómeno de la islamofobia tienen más de cinco siglos de antigüedad; las formas discursivas, socio-políticas, jurídicas e institucionales han variado a lo largo de la historia" (Adlbi Sibai, 2016, p. 126). En otras palabras, a pesar de que las estructuras de poder se mantienen a lo largo de la historia, las prácticas discursivas atienden a nuevas sutilezas de racismo, a las nuevas lógicas 
de funcionamiento del racismo (Wieviorka, 2006), y en este caso corresponde a un tipo específico de racismo cultural. Esta forma específica de racismo cultural

no sólo se manifiesta en el mercado laboral, la educación, la esfera pública, la guerra global contra el terrorismo o la economía mundial, sino también en el campo de batalla epistemológico acerca de la definición de las prioridades y la formulación de instituciones en el mundo actual. (Grosfoguel, 2014, p. 112).

Institucionalmente, desde el Consejo de Europa, el término islamofobia se define como "el temor o los prejuicios hacia el Islam, los musulmanes y todo lo relacionado con ellos. Ya tome la forma de manifestaciones cotidianas de racismo y discriminación u otras formas más violentas, la islamofobia constituye una violación de derechos humanos y una amenaza para la cohesión social" (Andújar, 2008).

\section{Marco metodológico}

Como metodología de investigación se ha considerado la metodología cualitativa de carácter etnográfico la más adecuada para acercarnos al fenómeno de estudio, los discursos entorno a la presencia del Islam en el espacio público. La metodología de este estudio forma parte de la tesis doctoral en construcción, y busca detectar las representaciones sobre los "otros" musulmanes en la sociedad española en general, y en Andalucía oriental específicamente. En este caso el trabajo de campo etnográfico ha sido realizado en la ciudad de Granada desde Septiembre de 2016 hasta Julio de 2017. Las técnicas que se han llevado a cabo principalmente han sido la observación participante y las entrevistas abiertas semidirigidas, colaborando con una entidad promotora de dinámicas comunitarias en el distrito Norte de la ciudad, y asistiendo y participando en debates, charlas y eventos relacionados con la presencia del Islam en los espacios públicos. Otra de las técnicas de producción de datos ha sido la realización de búsquedas de documentos digitales y oficiales relacionados con las percepciones u opiniones hacia el Islam como religión, y concretamente las noticias y comentarios relacionados con el evento de la ruptura del ayuno (Iftar) en una 
plaza céntrica, los jardines del triunfo de la ciudad de Granada, ${ }^{15}$ el sábado día 10 de Junio de 2017. Las unidades informativas han sido filtradas con las etiquetas de búsqueda "Iftar", "Ruptura del ayuno", "Ramadán” y "Granada”.

La etnografía virtual se presenta en este sentido como una herramienta metodológica útil para la aproximación al fenómeno de las representaciones sociales. Ya se conoce -ver Neve (2006)- que la interacción social se produce entre espacios analógicos y digitales, por lo que no se puede pensar en dos realidades por separado sino en una construcción en complementariedad; así los discursos, representaciones y percepciones sociales también son reflejados en los diferentes espacios de interacción.

Finalmente el análisis crítico del discurso se ha llevado a cabo a través de un sistema de códigos y categorías, generados a través del programa Atlas.ti, que han sido guiados por los objetivos de la investigación. El análisis del lenguaje escrito también recoge las intenciones y las expresividades que se reflejan, es decir, la forma en la que se transmite un mensaje. Detectando qué es lo que se le da importancia en la noticia redactada y de qué manera se resalta, y resaltando lo visible y lo intencionado de los textos escritos y los discursos de materiales audiovisuales. Los nombres de usuarios han sido modificados para garantizar el anonimato de las personas, por lo que los nombres que aparecen en los extractos discursivos no son reales.

\section{Análisis de datos}

No son pocos los eventos que han transcurrido relacionados con el Islam durante el transcurso del año 2017 en la ciudad de Granada -conferencias y seminarios en el ámbito académico organizados principalmente por

15 Algunos hallazgos demuestran que existió desde hace siglos en este territorio el "principal cementerio musulmán, que como se sabe se extendía desde la Puerta de Elvira hacia el oeste, y que ha ido siendo destruido de forma paulatina desde el siglo XVI" (Salvatierra Cuenca; García Granados; Jabaloy Sánchez, 1985-1987). En el año 1856 fue cuando se construyeron los jardines, produciéndose el traslado de la escultura católica en 1960 que estaba prevista para establecerse en otro lugar (http://www.granadadirect.com). En 1984 se realizaron en el Triunfo unos actos de desagravio y de rezo del rosario por la celebración de una obra de teatro llamada Demonis (López Cuenca; Vega, 2016). 
la Universidad de Granada o la Fundación Euroárabe; ${ }^{16}$ Jornadas Islam y Espacio Público (destinadas a los y las técnicas de las entidades sociales) organizadas por la delegación del gobierno regional (andaluz en su caso); eventos como el Iftar en varios puntos de la ciudad (en el centro el 10 de Junio, en el norte el 20 de Junio, y en la mezquita Omar el 17 de Junio)- entre otros varios. Los principales temas que generan discusión en los eventos oficiales y en los espacios de debate son los prejuicios y estereotipos acerca del Islam (sobre todo en la figura de la mujer musulmana), relacionados con los medios de comunicación. Por ofrecer solo un ejemplo, durante mi trabajo de campo tuve la oportunidad de asistir y parcipar en un mesa redonda sobre Islam y Espacio Público, organizada por la Junta de Andalucía (gobierno regional), Cooperación y Desarrollo con el Norte de África (CODENAF) y la Asociación Tres Culturas, en la que se realizaron discusiones en torno al Islam, la secularización, la legislación y el espacio público. Así lo recogí en su momento en mi diario de campo:

[...] la segunda mesa redonda en la que tengo el placer de escuchar a Fátima, Mounir y Eva Francés. Ésta empieza con la reflexión: ¿neutralidad o legislación?. La primera ponente: "los musulmanes estamos condenados a salir a la calle" refiriéndose a su visibilización para luchar contra las estigmatizaciones. "Los medios hablan de detenciones pero no de liberaciones". También se debate sobre cómo se representan las religiones en el espacio público [...].El segundo ponente comienza hablando del acuerdo del año 1992 como una trampa, en el cual no se contempló la financiación y mediante el cual se creó la fundación de pluralismo y convivencia como una estrategia de control.. El reconocimiento pero no la concesión de derechos se traduce en islamofobia institucional. La última ponente, Eva Francés, nos da una charla sobre la regulación del velo islámico en el espacio público español. Como la iglesia católica está representada por un Estado tiene más derechos (y más convenios) (Nota diario de campo, Jornadas Islam y Espacio Público, jueves 23 de Febrero de 2017).

Los casi 11 meses de trabajo de campo han dado para muchos registros en el cuaderno de campo pero en específico se han analizado los relacionados con

16 La Fundación Euroárabe de Altos Estudios es una institución de carácter académico, social y cultural que fomenta la cooperación entre Europa y el Mundo Árabe. 
la convivencia y la diversidad religiosa. En el transcurso del trabajo etnográfico, a finales del mes de Mayo, se propuso la iniciativa de generar unos encuentros entre los (y hablo en masculino) diferentes representantes de las diversas confesiones que están presentes en el territorio de intervención (Norte) y que han sido declaradas de notorio arraigo, lo que pronto pasaría a llamarse "mesa de diálogo interreligioso". "La mesa de diálogo interreligioso se ha gestado en un contexto de islamofobia creciente y ferviente y por ello se ha considerado necesario como recurso social y de resolución de conflictos" (nota diario de campo, 30 de Mayo de 2017). Esta iniciativa se encuentra en proceso de búsqueda de apoyos gubernamentales y de consolidación en el tiempo.

Varias son las exposiciones públicas que han realizado las diversas comunidades musulmanas para defender sus posiciones ante los discursos islamófobos que se presentan con la justificación de los ataques terroristas. En concreto nos centraremos en analizar uno de los eventos que más polémica ha suscitado en las redes y medios sociales virtuales, la ruptura del ayuno (Iftar) que se celebró con posterioridad a los ataques perpetrados en junio en Londres. El día 10 de Junio del año 2017 se celebró en Granada un acto público con el eslogan "Conoce el Ramadán" coincidiendo con el momento de ruptura de ayuno (Iftar) para los musulmanes en el mes de Ramadán. Fue el primer acto público y abierto compartido por las comunidades de musulmanes en Granada. El acto fue organizado por la Agrupación Islámica de Granada y el colectivo Cultura sin Rechazo, y en colaboración con la Fundación Euroárabe y el Ayuntamiento de Granada. Asistí al evento como observadora participante, ya que realizaban actividades y mi intención era ir a todos los eventos relacionados con el Islam, que no son pocos en la ciudad de Granada. El lugar elegido fueron los Jardines del Triunfo,

[...] es una plaza con jardines que se encuentra en el centro de la ciudad, de las pocas zonas que podríamos considerar "verdes" (solo por tener vegetación) en el centro de la ciudad. Esta plaza tiene varias "calles" en vertical y en horizontal, una más ancha en el centro, intercaladas por zonas con árboles, flores y algunas fuentes. La plaza está algo inclinada y en la parte superior encontramos una estatua de la virgen de la Inmaculada y una fuente, que casi se extiende de un lado al otro del parque, pero a la que no se puede acceder por la presencia de vallas. La periferia del conjunto también se encuentra rodeada de barrotes (nota Diario de Campo, 10 de junio 2017). 
Hubo varias actividades destinadas al aprendizaje de aspectos culturales relacionados con el Islam, tanto para niños y niñas como para personas adultas: talleres de manualidades para niños, pintura de manos con henna (tinte natural), taller para deconstruir rumores sobre el Islam, etc. En este último las cuestiones que más se nombraron como prejuicios o estereotipos hacia esta religión estaban orientados al papel de la mujer como sumisa o como dominada principalmente. Las actividades comenzaron alrededor de las 20:00 horas, y en ese momento ya había algunas decenas de personas tanto participando como observando, aparentemente musulmanes o no, extranjeros y nacionales, era un lugar que acogía una gran diversidad. Las actividades y talleres se realizaron en la parte superior de los jardines, mientras que la mesa con la comida, aportaciones de las comunidades musulmanas y de los demás participantes, se encontraba ubicada en una de las arterias principales horizontales de los jardines. En el camino principal (vertical) se comenzaron a estirar varias decenas de alfombras para el momento de la ruptura del ayuno. Cada vez se aglutinaban más y más personas en la plaza y observadores a su alrededor. A las 21:35, con la caída del sol, comenzó la ruptura del ayuno con dátiles y leche. Todos los asistentes, tanto musulmanes como no musulmanes, disfrutaban de los alimentos ofreciéndose unos a otros. Tras la ruptura, se llevó a cabo el rezo $\left(\right.$ Maghrib ${ }^{17}$ ) colectivo y posteriormente se procedió a desplegar el banquete de alimentos: harira (sopa tradicional marroquí), dulces, pastas, bizcochos, frutas variadas, etc. Este momento fue en el que se produjo un mayor acercamiento entre los y las asistentes al evento, hablaban sobre alimentos, tradiciones y costumbres, creencias y otros aspectos de la vida en la ciudad. Tras la comida, mientras las personas participantes recogían todo el despliegue de medios, se sirvió té moruno (una mezcla de té con hierbabuena). Antes de las 23:30 todo estaba recogido y los asistentes comenzaban a marcharse.

Días posteriores al evento descrito comenzaron a aparecer en las redes sociales y en los medios de comunicación virtuales noticias y comentarios que desataron un debate relacionado con la presencia del Islam en el espacio público. Por un lado, detractores de la iniciativa por considerarlo un espacio católico, por la presencia de la virgen de la Inmaculada en tal espacio;

17 El Magrib es uno de los cinco rezos (Salat) que llevan a cabo a diario las personas musulmanas. Los cinco son: Fayr, Dujur, Asr, Magrib e Isha. 
$y$, por otro, defensores de los valores multiculturales e interculturales para una convivencia pacífica. Los sectores de la población descontentos con el evento (principalmente conservadores y partidos con tendencia derechista) han sido los que han incentivado la polémica alrededor de éste, tomando la iniciativa de convocar un "acto de desagravio" para rezar el rosario en el mismo espacio público. Los primeros comentarios que sacaban el debate a relucir en las redes fueron de militantes políticos de partidos de tinte conservador, como Partido Popular, Ciudadanos y VOX.

En este sentido nos hemos centrado en analizar las estructuras y el contenido de las unidades informativas digitales relacionadas con el conflicto, así como los comentarios surgidos de las mismas. Los medios simpatizantes de la religión islámica muestran una descripción de los hechos del Iftar (ruptura del ayuno), mientras que los noticiarios locales simpatizantes con otros credos o ideologías políticas hacen hincapié en la polémica o el rechazo que produjo tal acto a ciertos sectores de la población. De las noticias analizadas en los diferentes medios digitales con las categorías "Iftar", "Ruptura del ayuno" "Ramadán" y "Granada" podemos apuntar que sólo las webs relacionadas con el mundo islámico son las que presentan una descripción de la noticia, sin resaltar la polémica suscitada por ciertos sectores de población.

De los diferentes noticiarios digitales analizados podemos señalar que la mayoría de los titulares se centran en destacar la polémica posterior al evento con algunas frases como "Convocan un acto de desagravio por la celebración de la ruptura [...]" (granadadigital.es, 12 Jun. 2017) “Polémica por la celebración en Granada [...]." (gentedepaz.es, 12 Jun. 2017) "Convocan un rezo del rosario para protestar [...]" (ideal.es, 12 Jun. 2017) “Granada crea otra polémica artificial [...]" (cadenaser.com, 12 Jun. 2017); mientras sólo dos medios describen la noticia del evento sin resaltar ninguna polémica con titulares como "Cientos de musulmanes granadinos celebran un iftar público en los Jardines del Triunfo" (webislam.com, 12 Jun. 2017). El análisis se ha centrado en las noticias una semana posterior al evento, pero los resultados obtenidos en la búsqueda se concretan en los dos días posteriores.

En los discursos de los comentarios analizados podemos comprobar cómo se equipara la religión a la nacionalidad, es decir, se exponen ideas atribuyendo las diferentes confesiones religiosas a identidades nacionales o no nacionales (extranjeras). Por un lado se atribuye el Islam a países extranjeros 
y el Catolicismo como religión e identidad nacional en España; ejemplo de ello lo podemos ver en frases como "[...] ir a un país musulmán a hacer una procesión de semana santa y verás lo que ocurre [...]” (Sonia, 12 Jun. 2017, Granada Digital); “[...] preguntándose en voz alta si sería posible colocar una pancarta alusiva a la celebración de una fiesta cristiana en cualquier país de mayoría musulmana” (Gente de Paz, 12 Jun. 2017); “[...] España es un país de tradición católica ¿ahora resulta que los que nos invaden han de tener prioridad [...]?" (español, 13 Jun. 2017, El Mundo); “Todo occidente es de cultura y tradición cristiana y greco-latina. Está en nuestra identidad” (MM, 13 Jun. 2017, El Mundo); "VOX Granada anima a 'quien quiera mostrar su fe' a 'hacerlo en desagravio, defendiendo las costumbres, valores y cultura heredadas'" (Ideal, 12 Jun. 2017). Estas construcciones no tienen en cuenta las diversificaciones existentes entre las personas practicantes del Islam y las construcciones herméticas de significados que están reproduciendo. Esto se traduce en un proceso de otrificación que sostiene y refuerza la idea de separación entre "unos y otros". En contraposición, también se han detectado discursos, aunque minoritarios, en los que se considera el Islam como una religión nacional: "muchos de los musulmanes residentes en Granada somos españoles, no sólo de nacimiento sino de genealogía, ciudadanos tan de pleno derecho dado por la Constitución española a celebrar nuestros ritos y fiestas como cualquier católico" (Moha, 12 Jun. 2017, Granada Digital), "Son tan granadinos como cualquier otro, por lo que tienen derecho a usar los espacios públicos de esta ciudad. Aún más cuando es para organizar una jornada de convivencia que solamente pretende dar a conocer otra cultura (que por cierto, tanto tiene que ver con nosotros), y abrir un poco la mente de esta ciudad tan cateta que tenemos" (matilde, 12 Jun. 2017, Ideal).

Otra de las categorías extraídas en el análisis en relación al espacio es la construcción simbólica del mismo y confusión entre el espacio público y el espacio privado. La constante comparación de espacios urbanos con espacios destinados para el culto es uno de los debates destacados en la polémica: "Es un acto irresponsable a los cristianos no se les ocurre rezar el Rosario en la Mezquita Mayor que regaló Granada a los musulmanes" (Lola, 12 Jun. 2017, Granada Digital); "La tolerancia debe ser recíproca, por ejemplo permitir el oficio de tinieblas de la Semana Santa dentro de una mezquita. Mientras no sucedan cosas como éstas, no creeré en el fácil discurso de la tolerancia" (Juan, 12 Jun. 2017, El Mundo); “[...] lo que aquí se discute es que les dejen el parque 
de la virgen del triunfo, coronado por la virgen del triunfo, a cuyos pies para más inri pusieron una pancarta de feliz ramadán. Es una cuestión de sentido común yo no vería correcto que ningún cristiano fuera en semana santa a poner en la mezquita feliz estación de penitencia, o feliz navidad" (anónimo, 12 Jun. 2017, El Mundo). Estos son algunos de los ejemplos discursivos extraídos sobre los que podemos constatar la construcción del espacio (Jardines del Triunfo) como un lugar por y para los católicos, comparándolo con la oración en templos musulmanes.

Un aspecto más a destacar es cómo se refleja la visibilización en espacios públicos de las diferentes comunidades musulmanas, siendo esta manifestada como una agresión, una provocación o una falta de respeto. Ejemplos de ello son discursos como: "El señor Paco Cuenca confunde tolerancia y respeto religioso con provocación. Convocar rezos musulmanes en la Virgen del Triunfo??" (12 Jun. 2017, Granada Digital); “[...] 'agraviar e insultar a miles de granadinos' por 'amparar' la celebración de un rezo colectivo de musulmanes a los pies de la Virgen del Triunfo, un lugar 'con un significado muy especial para los católicos', según la portavoz municipal popular, Rocío Díaz. [...] Díaz subraya que 'el respeto pasa por no herir la sensibilidad de nadie y en este caso está claro que se ha agraviado e insultado a miles de granadinos'" (12 Jun. 2017, El Mundo); “[...] el diputado nacional y portavoz de Ciudadanos Granada, Luis Salvador, ha señalado que el alcalde de Granada confunde tolerancia y respeto religioso con provocación al cuestionarse que se convocaran rezos musulmanes en la Virgen del Triunfo" (12 Jun. 2017, Cadena Ser).

El malestar generado por la elección y distribución del lugar para el evento también ha sido una de las categorías más recurrentes en el análisis, como ya se refleja en los ejemplos anteriores. Este malestar es generado por la presencia de personas o simbologías relacionadas con el Islam en los espacios públicos, sin cuestionar las presencias de éstas pertenecientes a otras religiones. Esto se refleja en discursos como: "A falta de unos días para que en Granada se celebre una de sus fiestas más importantes, la festividad del Corpus Christi, en la ciudad se ha levantado una agria polémica a resultas de la llamativa concentración que tuvo lugar el pasado sábado en los Jardines del Triunfo" (12 Jun. 2017, Gente de Paz); "La polémica suscitada obedece al lugar elegido para realizar la celebración, considerando la extensión de una ciudad como Granada [...] tal vez podría haberse evitado de elegir cualquier otra ubicación 
para la celebración del evento" (12 Jun. 2017, Gente de Paz); "Polémica en Granada por el permiso municipal para celebrar el fin del Ramadán ante la Virgen del Triunfo [...] el PP y las redes sociales critican el espacio elegido para la celebración, que censura también 'Granada Laica', que pide 'neutralidad institucional”" (12 Jun. 2017, El Mundo); "El alcalde socialista de la localidad andaluza ha permitido la celebración de unas jornadas de rezo y difusión del islam en el Campo del Triunfo, justo debajo de la imagen de la Inmaculada Concepción que se levantó en 1618" (12 Jun. 2017, Gaceta).

Una interesante cuestión que florece también del análisis son las exigencias o requerimientos por parte de algunos colectivos de no musulmanes de que la población musulmana se visibilice y estén a la cabeza de las reivindicaciones, por un lado, contra el terrorismo y, por otro, exigiendo la libertad de culto en países de mayoría musulmana. Algunos ejemplos de ello son los siguientes extractos de comentarios: “'Salieron todos ellos a mostrar su repulsa por los atentados en nombre de su religión? Sólo les preocupa la imagen que dan por su propio bien, para no verse fuera de Europa en un futuro" (Trinidad, 12 Jun. 2017, El Mundo), “[...] la comunidad musulmana también buscaba con esta jornada de 'convivencia' compartir sus tradiciones y 'dar una imagen de lo que realmente es el Islam', que 'está totalmente alejado de esas barbaries y actos criminales que vemos desgraciadamente tan a menudo'" (12 Jun. 2017, El Mundo); "Y respecto al Islam entiendo que la actitud en los países occidentales ha de ser la libertad de culto y el respeto total. Pero exigiendo lo mismo para los no musulmanes en países de mayoría islámica" (MM, 12 Jun. 2017, El Mundo).

Como vemos ya en el último ejemplo expuesto, los discursos justifican y reproducen la confrontación del binomio Occidente-Islam, siendo visto el primero como el moderno, democrático y desarrollado, y el segundo como lo contrario, atrasado, bárbaro y represor. Esta es una de las categorías que se encuentra presente de forma transversal en el análisis, al igual que la cuestión de género. Se puede destacar que la figura de la "mujer musulmana" aparece en estos discursos como el sujeto más reprimido y castigado. Otros ejemplos de esto serían: "[...] Creo que la diferencia es que el pensamiento occidental, y su religión o forma de vivir la religión ha evolucionado. y ahora mismo es más tolerable occidente [...]” (Pablo, 12 Jun. 2017, Granada Digital); “[...] la religión católica es infinitamente más tolerante y democrática que el islam. Lo mire por donde lo mire. No me venga con los Reyes católicos hombre!. El catolicismo 
ha evolucionado, el islam no" (Homero, 12 Jun. 2017, El Mundo); “[...] el islam es un atraso social y religioso, que somete a la mujer, que corta manos por robo, que apedrea a mujeres infieles, que obliga a casarse a las mujeres violadas con sus agresores, que concierta matrimonios de niñas con hombres mayores, que promueve la ablación de genitales femeninos, que incita al desprecio al infiel, que promueve la jihad o guerra contra el infiel, que castiga con penas severas cualquier manifestación de culto que no sea el islam, que prohíbe construcción de iglesias en sus países... podría seguir" (lider, 12 Jun. 2017, El Mundo).

Como último punto, hay que señalar que la representación en los diferentes noticiarios digitales de la participación en el evento de la ruptura del ayuno, ha sido destacando la presencia de los diferentes colectivos musulmanes, pocas veces resaltando la diversidad sociocultural que había presente. También se ha detectado un desconocimiento terminológico en relación con el Islam tanto en las noticias de prensa digital como en los comentarios de los usuarios. En este sentido también hay que puntualizar la correlación existente entre la tendencia ideológica de las líneas editoriales y los artículos con las ideas y argumentos que se exponen a colación de estos.

\section{Conclusiones}

En este trabajo hemos comprobado como el proceso de estigmatización del Islam en el contexto español sigue reproduciéndose en los discursos de algunos sectores de la ciudadanía y en los medios de comunicación, en la mayoría de los casos destacado como "agresor" de la "cultura nacional". Los principales debates entorno a la presencia del Islam en las sociedades occidentales se ven principalmente orientados en términos dicotómicos (Adlbi Sibai, 2016)- compatibilidad/incompatibilidad, modernidad/retrogradismo- y bajo el paraguas de los valores de la liberal-democracia, la libertad de expresión y la igualdad (haciendo hincapié en las cuestiones de género). En relación a la acomodación del Islam en tales sociedades se debate bajo los términos de "todo o nada" o "todos o ninguno"; por ejemplo, cuando se habla de musulmanes y musulmanas se tienden a relacionar tales categorías con poblaciones (in)migrantes, ignorando la gran diversidad que acogen dichos términos. Dicho de otro modo, se está produciendo un fenómeno de otrificación y racialización de las 
poblaciones o colectivos musulmanes que no se corresponde con la realidad del contexto español ni con una realidad universal y que da como resultado un proceso de alterización:

Son determinados grupos o individuos quienes hacen posible que se produzcan otredades, y es gracias a las ideologías -en tanto que cosmovisiones-como estas pueden permanecer en el tiempo y determinar de manera importante el desarrollo de relaciones sociales, traspasando los niveles meramente cognitivos e instaurándose en lo social, lo cultural, lo político, lo normativo[...] (Olmos Alcaraz, 2012, p. 64).

Se trataría de una separación entre un "nosotros" y los "otros" que se construye de forma inconsciente o consciente por determinados grupos sociales, y que relaciona Islam con extranjero y extranjero con barbarie. Esta relación no es ni mucho menos novedosa, algunos autores como Santamaría (2002) ya señalaban la identificación de inmigración y barbarie, en la que se genera una alterización principalmente de la inmigración "no comunitaria" y la existencia de una compleja relación entre alteridad, política y violencia. Ésta simplificación y homogeneización de colectivos que se construyen como diferentes, como los "otros", es alimentada por el racismo institucional y el desconocimiento sobre el Islam como religión, como podemos comprobar por el uso indiscriminado y erróneo de conceptos y categorías relativas; provocando una islamofobia creciente, tanto estructural como individualmente, cuando nos encontramos con aspectos relacionados con el Islam. Estas representaciones construidas de los "otros" se reflejan en las relaciones e interacciones sociales cotidianas pero también en la forma en la que se construye y gestiona una comunidad o sociedad.

Otro ejemplo en relación a la acomodación del Islam en la sociedad española sería la gestión de las demandas de tales poblaciones en los ámbitos educativo y laboral, como la adaptación de los menús escolares o de los horarios de trabajo para dar cabida al rezo o a otras tradiciones, que son percibidas como amenaza a la estructura social y su estabilidad/deseabilidad. Así "las respuestas políticas públicas a la diversidad religiosa se formulan a través de conflictos iniciales que se deben, en su mayoría, a una falta de reconocimiento público de estas prácticas" (Zapata-Barrero, 2017, p. 54). Otra de las principales ideas construidas bajo los prejuicios o estereotipos occidentalocéntricos entorno 
al Islam en España, y que hemos contrastado en el análisis empírico, es la anulada capacidad de decisión de las mujeres musulmanas.

Los medios de comunicación juegan un papel esencial en la construcción de procesos de alterización y en la generación de opinión pública, bajo determinados principios ideológicos, siendo parte del proceso de construcción de los imaginarios sociales. La presencia del Islam en el espacio público se percibe así por ciertos sectores de la población como una agresión o amenaza a los valores y a la cultural que consideran como tradicionales y nacionales, haciendo referencia a "su" identidad nacional, que en el caso estudiado se corresponden con los valores de una sociedad conservadora, católica, democrática y patriarcal. Se convierte entonces el espacio público en un espacio político con una gran carga ideológica, en el que no se trata simplemente de un espacio compartido o comunitario sino que es legislado y construido, física y simbólicamente, sobre unos presupuestos ideológicos (Delgado; Malet, [s.d.]).

\section{Referencias}

ADLBI SIBAI, S. La cárcel del feminismo: hacia un pensamiento islámico decolonial. México, D.F: Akal, 2016.

ALCANTUD, J. A. G. Lo moro revisitado. Dimensión estética, diversidad cultural, función crítica, fantasma social. Revista Internacional de Filosofía Política, n. 31, p. 29-48, 2008.

ÁLVAREZ DE MORALES Y RUIZ MATAS, C. Granada en la historia de al-Andalus. In: UNOS APUNTES sobre la Granada andalusí. Granada: Escuela de Estudios Árabes, 2008. Disponible en: <https://www.eea.csic.es/publicaciones-eea/unos-apuntessobre-la-granada-andalusi/granada-en-la-historia-de-al-andalus/>. Acceso: 15 sept. 2017.

ANDÚJAR, $\mathrm{N}$. El papel de los jóvenes musulmanes en la transformación del Islam. Revista de Estudios de Juventud, Madrid, n. 80, p. 61-75, 2008.

ARDUINO, E. Mujeres y feminismo en África poscolonial. Claroscuro, Rosario, n. 15, p. 129-147, 2016.

BLANCO, M. et al. Guía de comunidades y entidades musulmanas de Granada. Granada: Editorial Maristán, 2004. 
CHECA OLMOS, F. (Dir.). El Ejido: la ciudad-cortijo: claves socioeconómicas del conflicto étnico. Barcelona: Icaria, 2001. (Antrazyt, 166).

DELGADO, M.; MALET, D. El espacio público como ideología. In: URBANDOCS. [S.l.]: Fórum Español para la Prevención y la Seguridad Urbana, [s.d.]. p. 57-65. Disponible en: <http://www.fepsu.es/docs/urbandocs/URBANDOCl.pdf>. Acceso: 25 ago. 2017.

DIETZ, G. Mujeres musulmanas en Granada: discursos de formación de comunidad, exclusión de género y discriminación etno-religiosa. In: GARCÍA CASTAÑO, F. J.; MURIEL LÓPEZ, C. (Coord.). La inmigración en España: contextos y alternativas. Granada: Laboratorio de Estudios Interculturales, 2002. v. 2, p. 381-394.

DIETZ, G. La educación religiosa en España: ¿Contribución al diálogo intercultural o factor de conflicto entre religiones?. Estudios sobre las culturas contemporáneas, n. 28, p. 11-46, 2008.

ESPAÑA. Agencia Estatal Boletín Oficial del Estado. Ley Orgánica 7/1980, de 5 de julio, de Libertad Religiosa. 1980. Disponible en: <http://www.boe.es/buscar/doc. php?id=BOE-A-1980-15955>. Acceso: 10 jun. 2017.

ESPAÑA. Ministerio de Justicia. Detalle de entidades religiosas. 2017. Disponible en: <http://maper.mjusticia.gob.es/Maper/DetalleEntidadReligiosa.action?numeroInsc ripcion=021324>. Acceso: 15 sept. 2017.

GIMÉNEZ ROMERO, C. Pluralismo, multiculturalismo e interculturalidad. Educación y futuro: revista de investigación aplicada y experiencias educativas, n. 8, p. 11-20, 2003.

GROSFOGUEL, R. Las múltiples caras de la islamofobia. De Raíz Diversa, v. 1, n. 1, p. 83-114, 2014.

INSTITUTO NACIONAL DE ESTADÍSTICA. Padrón municipal a 1 de Enero. 2016. Disponible en: <http://www.ine.es/metodologia/t20/t203024566.htm>. Acceso: 15 jun. 2017.

JUNTA DE ANDALUCÍA. Sistema de Información Multiterritorial de Andalucía. Andalucía pueblo a pueblo - Fichas Municipales. 2016. Disponible en: <http://www.juntadeandalucia.es/institutodeestadisticaycartografia/sima/ficha.htm?mun=18087>. Acceso: 15 sept. 2017.

LÓPEZ CHAVES, P. Comunidades islámicas en la ciudad de Granada. Revista del Centro de Estudios Históricos de Granada y su Reino, n. 22, p. 187-208, 2010.

LÓPEZ CUENCA, R; VEGA, E. Granada: guía monumental. Granada: Cien-gramos, 2016.

MARTÍN MUÑOZ, G.; GROSFOGUEL, R. (Coord.). La islamofobia a debate: la genealogía del miedo al islam y la construcción de los discursos antiislámicos. Madrid: Casa Árabe, 2012. 
MORERAS, J. Conflictos en Cataluña. In: ATLAS DE LA INMIGRACIÓN MARROQUÍ EN ESPAÑA. Madrid: Taller de Estudios Internacionales Mediterráneos, 2004. p. 444-445.

MORERAS, J. ¿Integrados o interrogados? La integración de los colectivos musulmanes en España en clave de sospecha. In: HERNÁNDEZ PEDREÑO, M.; PEDREÑO CÁNOVAS, A. (Coord.). La condición inmigrante: exploraciones e investigaciones desde la Región de Murcia. Murcia: Universidad de Murcia, 2005. p. 227-240.

MORERAS, J.; TARRÉS, S. Guía para la gestión de la diversidad religiosa en cementerios y servicios funerarios. Madrid: Observatorio del pluralismo religioso en España, 2013.

NEVE, E. Exploración de espacios y lugares digitales a través de la observación flotante. Una propuesta metodológica. In: CONGRESO ONLINE DEL OBSERVATORIO PARA LA CIBERSOCIEDAD, 3., 2006. Actas... [S.1.], 2006.

NOOR, F. A. El terror y la política de contención: análisis del discurso de la guerra contra el terror y los mecanismos del poder. In: MARTÍN MUÑOZ, G.; GROSFOGUEL, R. (Coord.). La islamofobia a debate: la genealogía del miedo al islam y la construcción de los discursos antiislámicos. Madrid: Casa Árabe, 2012. p. 75-98.

OBSERVATORIO ANDALUSÍ. Estudio demográfico de la población musulmana. 2016. Disponible en: <http://observatorio.hispanomuslim.es/estademograf.pdf>. Acceso: 15 jun. 2017.

OBSERVATORIO ANDALUSÍ. Informe anual 2016: institución para la observación y seguimiento de la situación del ciudadano musulmán y la islamofobia en España. UCIDE, 2017a. Disponible en: <http://ucide.org/es/content/actualidadpoblaci\%C3\%B3n-musulmana-en-espa\%C3\%Bla>. Acceso: 1 jul. 2017.

OBSERVATORIO ANDALUSÍ. Informe especial J/2016: institución para la observación y seguimiento de la situación del ciudadano musulmán y la islamofobia en España, Incidencias e islamofobia. UCIDE, 2017b. Disponible en: <http://ucide.org/sites/ default/files/revistas/isj16.pdf>. Acceso: 1 jul. 2017.

OLMOS ALCARAZ, A. Cuando migrar se convierte en estigma: un estudio sobre construcción de alteridad hacia la población inmigrante extranjera en la escuela. Imagonautas: Revista Interdisciplinaria Sobre Imaginarios Sociales, v. 1, n. 2, p. 62-85, 2012.

OLMOS ALCARAZ, A. “Los malos a mí no me llaman por mi nombre, me dicen moro todo el día": una aproximación etnográfica sobre alteridad e identidad en alumnado inmigrante musulmán. Empiria: Revista de Metodología de Ciencias Sociales, n. 38, p. 85-107, 2017. 
ROSÓN LORENTE, F. J. Muslimofobia vs. muslimofilia: comunidades étnicas en la ciudad de Granada. In: GARCÍA CASTAÑO, F. J.; MURIEL LÓPEZ, C. (Coord.). La inmigración en España: contextos y alternativas. Granada: Laboratorio de Estudios Interculturales, 2002. v. 2, p.45-53.

ROSÓN LORENTE, J. R. Discrepancias en torno al uso del término islamofobia. In: MARTÍN MUÑOZ, G.; GROSFOGUEL, R. (Coord.). La islamofobia a debate: la genealogía del miedo al islam y la construcción de los discursos antiislámicos. Madrid: Casa Árabe, 2012. p. 167-190.

SALVATIERRA CUENCA, V;; GARCÍA GRANADOS, J. A.; JABALOY SÁNCHEZ, M. E. Necrópolis medievales II: hallazgos sueltos en la provincia de Granada. Cuadernos de Estudios Medievales y Ciencias y Técnicas Historiográficas, n. 14-15, p. 211-224, 1985-1987. Disponible en: <http://digibug.ugr.es/bitstream/10481/30280/1/CEM-014-015.001Art\%C3\%ADculo-011.pdf>. Acceso: 15 jun. 2017.

SANTAMARÍA, E. Inmigración y barbarie. La construcción social y política del inmigrante como amenaza. Papers: Revista de Sociología, n. 66, p. 59-75, 2002.

TARRÉS CHAMORRO, S.; ROSÓN LORENTE, J. ¿Musulmanes o inmigrantes? La institucionalización del islam en España (1860-1992). Revista CIDOB d'Afers Internacionals, n. 115, p. 165-185, 2017.

TORRADEFLOT, F. Religiones y pluralismo. Las vías del diálogo interreligioso en España. RIPS, v. 11, n. 3, p. 15-38, 2012.

UCIDE. Historia de la Unión de Comunidades Islámicas de España (Ucide). [s.d.]. Disponible en: <http://ucide.org/es/content/historia-de-la-un\%C3\%AD-de-comunidadesisl\%C3\%Almicas-de-espa\%C3\%B1-ucide>. Acceso: 20 jun. 2017.

WIEVIORKA, M. La mutación del racismo. Migraciones, n. 19, p. 151-163, 2006.

ZAPATA-BARRERO, R. La diversidad religiosa más allá del estado-nación y del multiculturalismo. Claves de Razón Práctica, n. 250, p. 50-59, 2017.

Recebido: 29/09/2017 Aceito: 11/05/2018 | Received: 9/29/2017 Accepted:5/11/2018 